\title{
Capítulo
}

4

\section{Desmistificando a adoção de Learning Analytics: um guia conciso sobre ferramentas e instrumen- tos}

\author{
Elyda Freitas, Taciana Pontual Falcão e Rafael Ferreira Mello
}

\begin{abstract}
Learning Analytics (LA) is an emerging topic within the field of information technology in education. Its main objective is to provide evidence-based information about data to assist teachers and students in the teaching-learning process. LA tools can assist in several activities such as identifying students at risk. However, the simple adoption of LA tools does not guarantee the improvement in teaching or the engagement of teachers and students. In this sense, the literature proposes a set of instruments to carry out a detailed analysis of educational institutions' expectations and needs about the adoption of LA. These instruments identify the institutions' primary needs and examine what students, teachers, and institutional managers expect to achieve with the use of LA. Once the decision to use LA is made, a new challenge emerges: monitoring the adoption. It is crucial to identify the progression and limitations during the process of adopting and using LA. For this, one of the strategies that can be used is the application of a maturity model. In this context, this chapter presents introductory concepts about LA as well as instruments and tools relevant to its adoption and monitoring in educational institutions.
\end{abstract}

\section{Resumo}

Learning Analytics (LA) é um tópico de pesquisa emergente na área de Informática na Educação. Seu principal objetivo é fornecer evidências baseadas em dados a fim de auxiliar professores e alunos na melhoria dos processos de ensino e aprendizagem. Ferramentas de LA podem auxiliar em diversas atividades, como identificar alunos em risco de evasão. Contudo, a adoção de ferramentas de LA não garante o engajamento dos professores e estudantes. Nesse sentido, a literatura propõe um conjunto de instrumentos que ajudam a realizar uma análise detalhada das expectativas e necessidades de instituições de ensino em relação à adoção de LA. Esses instrumentos identificam as principais 
necessidades das instituições e examinam o que alunos, professores e gestores esperam alcançar com a utilização de LA. Uma vez tomada a decisão de usar LA, surge um novo desafio: o monitoramento. É importante identificar quais são as etapas necessárias para evoluir no uso de LA e também as limitações de cada instituição. Para isso, uma das estratégias que podem ser usadas é a aplicação de um modelo de maturidade. Diante desse contexto, este capítulo apresenta os conceitos introdutórios sobre LA assim como instrumentos e ferramentas relevantes para a sua adoção e monitoramento em instituições de ensino.

\subsection{Introdução}

As preocupantes taxas de retenção e evasão no ensino superior, tanto na Educação a Distância $(\mathrm{EaD})$ quanto em cursos presenciais, levam as universidades a estarem sempre em busca de métodos, ferramentas e abordagens que possam contribuir para melhorar os índices de desempenho dos estudantes e de sucesso na graduação.

Neste processo, Ambientes Virtuais de Aprendizagem (AVA), sistemas acadêmicos (como SIGA e SIGA-A) e diversas ferramentas online têm sido cada vez mais adotados. Na EAD, os AVA representam a sala de aula virtual, onde o ensino ocorre. Porém, em cursos presenciais, tais ambientes e outras ferramentas online têm ganhado cada vez mais espaço como apoio para disponibilização de materiais e atividades e para comunicação e colaboração.

Em particular, diante da pandemia que assolou o mundo no ano de 2020 e forçou as IES (Instituições de Ensino Superior) a migrarem repentinamente para um modelo totalmente a distância, a importância e a utilidade de tais ferramentas tornaram-se ainda mais evidentes, reforçando e acelerando a tendência mundial para modelos híbridos de ensino (semi-presenciais).

Com a adoção cada vez maior de ferramentas online de apoio ao ensino, aprendizagem e gestão acadêmica, cresce também a quantidade de dados educacionais armazenados, dados esses que podem ser valiosos para a compreensão do contexto, a identificação de riscos e dificuldades, o planejamento didático e o apoio ao feedback aos estudantes.

Com isso, tornou-se necessária a utilização de técnicas automáticas para extrair informação desses dados. Diante deste contexto, técnicas de Learning Analytics (LA) têm sido cada vez mais aplicadas para compreensão e otimização dos processos de aprendizagem e dos ambientes onde eles ocorrem (Lang et al., 2017). Uma característica fundamental da LA é aumentar a capacidade de diferentes stakeholders para participarem de forma ativa no planejamento e execução de intervenções e aplicações baseadas em evidências (Dyckhoff et al., 2012; Clow, 2012). Várias aplicações foram propostas nesta linha, incluindo visualização de dados (Verbert et al., 2013; Guerra et al., 2020); envio de feedback personalizado (Pardo et al., 2019; Cavalcanti et al., 2020); formação de grupos (Miranda, Mello, \& Nascimento, 2020; Miranda, Mello, Castro, et al., 2020); e análise dos dados textuais dos alunos (Mello et al., 2019; Passero et al., 2020; Rolim et al., 2019).

Contudo, do ponto de vista institucional, a implementação de abordagens e ferramentas de análise de aprendizagem de forma eficaz não é simples e exige o engajamento de diferentes partes interessadas, como alunos, professores e gestores. Embora várias 
instituições tenham começado a elaborar suas próprias políticas de LA (Tsai \& Gasevic, 2017), muitas ainda não possuem o conhecimento necessário para implementá-las de forma eficaz. Por isso, a adoção institucional de processos de LA em vários locais do mundo, como a América Latina, é pontual e tem baixo níveis de maturidade (Cechinel et al., 2020).

Nesse sentido, diferentes iniciativas têm surgido ao redor do mundo para facilitar a adoção e gerenciamento de ferramentas de LA. No contexto europeu, o projeto SHEILA (Supporting Higher Education to Integrate Learning Analytics) visa auxiliar as universidades europeias na adoção de LA (Tsai et al., 2018) com um framework para mapear os requisitos da instituição como contexto político, principais partes interessadas, estratégia de engajamento, a capacidade interna de efetuar mudanças e estruturas de monitoramento e aprendizagem. Baseado no SHEILA, o projeto LALA (Learning Analytics in Latin America) propõe uma série de passos que precisam ser efetuados para desenvolvimento de soluções de LA levando em consideração o contexto da América Latina, melhorando sua qualidade, relevância e eficiência (Hilliger et al., 2020).

Essas iniciativas são focadas principalmente na adoção inicial de LA e não no seu monitoramento ao longo do tempo. Contudo, recentemente foi proposto um modelo de maturidade para uma análise contínua de diferentes aspectos envolvidos na adoção de LA em instituições de ensino (E. Freitas et al., 2020). Este modelo apresenta, de forma clara e objetiva, os principais direcionamentos que a instituição tem que seguir para alcançar o sucesso na utilização de ferramentas de LA. Diante deste contexto, este capítulo de livro apresenta os principais conceitos necessários para pesquisadores e gestores entenderem mais sobre o potencial de utilizar LA, quais questões devem ser levadas em consideração na adoção inicial e como monitorar o progresso no uso dessas ferramentas ao longo do tempo.

\subsection{Learning Analytics}

Learning Analytics (LA) é um campo de pesquisa recente, que se utiliza dos dados resultantes da interação dos usuários com os Sistemas de Gestão de Aprendizagem - bem como com outras fontes - para realizar análises que auxiliam o aluno e o professor a compreender e avaliar o processo de ensino e aprendizagem, permitindo a tomada de decisões e a melhoria desses processos (E. L. S. X. Freitas et al., 2019). A Society for Learning Analytics Research (SoLAR ${ }^{1}$ ) caracteriza LA como: "a medição, coleta, análise e descrição de dados sobre estudantes e seus contextos, com o propósito de entender e otimizar o aprendizado e os ambientes em que ocorrem". Pode-se afirmar, portanto, que o objetivo principal dessa nova área é a melhoria dos processos de ensino e aprendizagem.

Segundo explicam Gewerc et al. (2016), é comum que os professores desconheçam o que seus estudantes fazem para aprender. LA, por sua vez, possui ferramentas que permitem revelar esses caminhos seguidos pelos estudantes. Além disso, diversos tipos de aplicações são possíveis por meio da utilização das técnicas de LA. Por exemplo, é possível prever o desempenho de estudantes em um curso e realizar ações a fim de evitar que o estudante falhe ou abandone o referido curso. Pode-se também compreender o comportamento e o perfil dos estudantes no ambiente de aprendizagem: quais os

\footnotetext{
${ }^{1}$ https://www.solaresearch.org/
} 
tipos de atividades mais adequadas àquele estudante, quais estão engajados e quais não colaboraram em atividades em grupo (E. L. S. X. Freitas et al., 2019).

Em síntese, LA pode ser útil tanto aos estudantes, como um instrumento de apoio na autorreflexão sobre os seus processos de aprendizagem (Santos et al., 2012); quanto aos professores, provendo insumos para auxílio aos alunos e para avaliação de objetos de aprendizagem (Dyckhoff et al., 2012). Conforme explicam Raghuveer \& Tripathy (2014), a análise de experiências coletivas de alunos com comportamento similar pode beneficiálos na determinação dos requisitos de aprendizagem. Isto pode então permitir obter uma compreensão mais aprofundada e encontrar o melhor processo de aprendizagem (Sun et al., 2016).

Conforme explicam (Virvou et al., 2015, p. 3), LA "tenta preencher a lacuna entre a singularidade de um usuário e o montante de dados disponíveis". Esta dificuldade pode ser vista com maior intensidade em cursos conhecidos como MOOC (Massive Open Online Course, em português, Curso Online Aberto e Massivo), os quais têm centenas de alunos aprendendo gratuitamente a partir de recursos online e que são avaliados especialmente por meio de ferramentas automáticas (Baneres et al., 2016). Dada a grande quantidade de alunos, nessa modalidade de educação online os instrutores não conseguem direcionar muito tempo a cada um dos estudantes (Ruiz et al., 2014). Por esta razão, faz-se necessária a utilização de técnicas de avaliação automatizadas que permitam um acompanhamento mais próximo.

Visto que em muitos casos os professores possuem uma grande quantidade de alunos, LA pode auxiliar na tarefa de acompanhá-los, permitindo uma intervenção rápida ou até mesmo automática para estudantes que apresentem dificuldades. Também, é possível a identificação de objetos de aprendizagem com problemas a fim de tomar ações corretivas, sendo possível ainda avaliar a efetividade das intervenções.

Greller \& Drachsler (2012) sintetizam os benefícios relacionados à utilização de LA: (1) a aprendizagem personalizada tem o potencial de reduzir os custos e, ao mesmo tempo, criar experiências de aprendizagem mais eficazes; (2) permite a alunos e professores autorreflexão sobre os processos de ensino-aprendizagem; (3) permite aos professores avaliar processos de ensino inovadores e, ao governo, avaliar as Instituições de Ensino Superior (IES); (4) pode ajudar os alunos a verificar seu desempenho com relação aos demais; e (5) possibilita às IES acompanhar e diminuir a taxa de desistências.

Apesar do entusiasmo em torno de LA e de seus benefícios, Yassine et al. (2016) explicam que as instituições têm sido lentas na adoção dessa técnica. Uma das razões para isso é que a adoção de LA é uma tarefa complexa, que exige da instituição a capacidade de responder em diferentes frentes de trabalho, sejam elas de gestão, pedagógicas ou tecnológicas. Conforme explicam (Sclater et al., 2016, p. 3), LA "apresenta desafios adicionais únicos relacionados à história e cultura do ensino superior, dificuldades metodológicas ao medir o 'aprendizado', ferramentas e processos imaturos e uma lentidão até que os resultados possam ser avaliados". Somem-se a isso, ainda, as questões éticas e de privacidade envolvidas na utilização de dados educacionais.

Diante desse contexto, diversas iniciativas têm sido propostas para orientar as instituições de ensino na adoção de LA. Discutiremos a seguir sobre ferramentas que podem 
Tabela 4.1. Diferenças entra LA e MDE segundo Siemens \& Baker (2012).

\begin{tabular}{|c|c|c|}
\hline Tópico & Learning Analytics (LA) & $\begin{array}{l}\text { Mineração de Dados Educacio- } \\
\text { nais (MDE) }\end{array}$ \\
\hline Descoberta & $\begin{array}{l}\text { Prover informações para decisões } \\
\text { de humanos. }\end{array}$ & $\begin{array}{l}\text { Algoritmos de descoberta auto- } \\
\text { mática. }\end{array}$ \\
\hline Redução & $\begin{array}{l}\text { Ênfase em entender sistemas } \\
\text { como todo e suas complexidades. }\end{array}$ & $\begin{array}{l}\text { Enfase em reduzir a complexi- } \\
\text { dade dos sistemas para compo- } \\
\text { nentes ou análises individuais. }\end{array}$ \\
\hline Origem & $\begin{array}{l}\text { LA originou-se a partir de con- } \\
\text { ceitos como web semântica, cur- } \\
\text { rículo inteligente e intervenções } \\
\text { sistemáticas. }\end{array}$ & $\begin{array}{l}\text { MDE se originou de softwares } \\
\text { educacionais, modelagem de alu- } \\
\text { nos, com influência considerável } \\
\text { da comunidade de predição de re- } \\
\text { sultados de curso. }\end{array}$ \\
\hline Adaptação e personalização & $\begin{array}{l}\text { Foco em empoderar professores e } \\
\text { alunos a tormar decisões. }\end{array}$ & $\begin{array}{l}\text { Foco em processos automáticos, } \\
\text { sem intervenção humana. }\end{array}$ \\
\hline Técnicas & $\begin{array}{l}\text { Análise de redes sociais, análise } \\
\text { de sentimentos, análise de dis- } \\
\text { curso, predição de sucesso de } \\
\text { aluno, modelos de sensemaking. }\end{array}$ & $\begin{array}{l}\text { Classificação, agrupamento, mi- } \\
\text { neração de relacionamentos, vi- } \\
\text { sualização. }\end{array}$ \\
\hline
\end{tabular}

ser utilizadas para a adoção de LA bem como instrumentos para apoiar as instituições. Por fim, estendemos o debate para vislumbrar o futuro da adoção de LA, por meio de um Modelo de Maturidade, o qual visa orientar a adoção e o progresso das instituições nessa área. Contudo, antes de apresentar essas informações é importante diferenciar LA de outras áreas bastante comuns dentro do contexto de informática na educação.

\section{3. Áreas Relacionadas}

A área de Learning Analytics surgiu praticamente na mesma época das pesquisas em Mineração de Dados Educacionais (do inglês Educational Data Mining - EDM). Ambas as áreas buscam melhorar a qualidade da educação ao analisar grandes quantidades de dados para extrair informações úteis para alunos, professores e gestores. Contudo, a Tabela 4.1 apresenta as principais diferenças entre essas áreas (Siemens \& Baker, 2012).

Diante destas diferenças, a mais importante é a participação de professores e alunos na tomada de decisão. Enquanto LA foca em prover informações para que professores e alunos decidam, MDE foca em criação de sistemas de decisão automáticas.

Outra área bastante relacionada a LA é a Academic Analytics (AA). O foco de LA e AA é o mesmo: melhorar o processo de ensino aprendizagem e evitar problemas como retenção e evasão. Além disto, ambas as áreas utilizam metodologias e técnicas similares. Contudo, o foco principal de AA são gestores e stakeholders que têm o poder de tomar decisões institucionais, enquanto LA foca mais em professores e alunos (Campbell et al., 2007). 


\subsection{Adoção de Learning Analytics}

Fazer uso de dados educacionais de forma sistemática, automatizada, aplicada e útil para a comunidade educacional não é um processo simples. Muitas IES atualmente ainda enfrentam dificuldades para implantar um processo de Learning Analytics (Gašević et al., 2019), pois isso implica em uma integração ao planejamento estratégico da IES, aceitação e engajamento dos stakeholders, infraestrutura tecnológica, expertise na área, política consolidada de proteção e privacidade de dados (Tsai et al., 2018; Ferguson et al., 2014). Existem também receios comuns relacionados à possível implantação de LA, como a legalidade e os limites no uso de dados pessoais e o risco de consequências negativas a partir do uso de LA (Greller \& Drachsler, 2012).

Tsai et al. (2018) consideram três grandes desafios para a implantação de LA em IES. O primeiro é a demanda por recursos (tecnológicos, financeiros e humanos). Implantar LA exige manipulação complexa de dados e integração e desenvolvimento de ferramentas, que podem demandar tecnologias mais avançadas do que a IES dispõe. O investimento financeiro torna-se um ponto fundamental para o sucesso do projeto. Além disso, existe a demanda por profissionais que possuam o conhecimento técnico necessário para lidar com os dados, e tempo de serviço alocado para tal. Os próprios usuários (professores, estudantes e gestores) também precisam desenvolver algumas habilidades de análise e interpretação de dados que lhes permitam tomar decisões baseadas em evidências, sejam sobre sua prática docente, seus métodos de estudo, ou as políticas da instituição (Tsai et al., 2018).

O segundo grande desafio, segundo Tsai et al. (2018), engloba as questões éticas e de privacidade. A coleta de dados dos estudantes pode incluir dados sensíveis (como de vulnerabilidade socioeconômica, por exemplo), além de um sentimento de estar sendo vigiado, o que gera resistência. Um dilema que permeia a LA é que um feedback personalizado e de qualidade exige algum grau de identificação, em detrimento do total anonimato nos dados. Além disso, o consentimento formal dos estudantes ao ingressar na instituição para conceder acesso aos seus dados pode não ser transparente, pois é difícil prever todos os usos, riscos e consequências disso em uma instituição que possui uma política de LA. Em um campo tão dinâmico, mudanças são esperadas, o que poderia implicar em atualizações constantes e ineficientes em termos de consentimento - o que apresenta mais um dilema para gestores (Tsai et al., 2018).

Por fim, Tsai et al. (2018) elencam como terceiro grande desafio o engajamento dos stakeholders. Existe uma grande variação, nas comunidades acadêmicas, de entendimento e percepção de possíveis benefícios decorrentes do uso de LA, o que pode ter grande impacto para o sucesso do projeto, principalmente a nível de gestão. Da parte dos professores, ainda há pouca pesquisa em LA que investe no suporte às decisões pedagógicas baseadas em evidências, em detrimento de uma maior quantidade de trabalhos técnicos, focados na mineração e análise dos dados. A transposição desses resultados para um uso efetivo na prática docente cotidiana ainda é pouco clara, o que gera resistência em professores, em especial aqueles que têm pouca intimidade com tecnologias. Por fim, mas não menos importante, os estudantes, que são o grupo de usuários finais a quem as soluções de LA mais beneficiariam, são raramente ouvidos nos planejamentos institucionais (Tsai et al., 2018). 
Macfadyen et al. (2014) argumentam que IES precisam definir políticas e estratégias que contemplem as particularidades da instituição, incluindo aspectos culturais e estruturas e práticas sociais. Políticas de LA muito possivelmente serão disruptivas, visto que representam novas abordagens a serem integradas aos processos de ensino e gestão. Toda mudança, em especial aquelas que alteram um modo de funcionar consolidado e familiar a toda uma comunidade, gera receio e resistência. Para evitar frustrações e fracassos, é muito importante adotar um instrumento sistemático de planejamento e adoção de LA, mas também estratégias de monitoramento que permitam avaliar o sucesso das técnicas de LA, na busca por transformações organizacionais e não apenas melhorias pontuais (como melhorias de infraestrutura ou melhor compreensão das questões legais dentro da IES) (Gašević et al., 2019). Segundo Gašević (2018), para garantir benefícios à instituição, a implementação de ferramentas e métodos de LA precisa estar fortemente integrada aos processos de ensino e aprendizagem no nível da sala de aula, e aos processos de tomada de decisão no nível institucional (Gašević, 2018).

\subsubsection{Instrumentos de Apoio à Adoção de Learning Analytics}

Dada a complexidade envolvida na adoção de Learning Analytics, existem instrumentos que podem ser usados para apoiar esse processo e assim difundir a implantação de técnicas de LA nas IES. A seguir são apresentados alguns exemplos, que convergem para algumas dimensões fundamentais: infraestrutura tecnológica adequada, liderança institucional, cultura organizacional, capacidade de recursos humanos e estratégia (Colvin et al., 2017), os quais são consonantes com os desafios apresentados anteriormente.

O Analytics Maturity Index for Higher Education (Bichsel, 2012) possui seis dimensões: cultura, processo, dados / ferramentas, investimento, expertise e governança / infraestrutura. Cada uma dessas dimensões é avaliada em cinco níveis de maturidade, auxiliando instituições a determinar seu progresso de maneira sistemática.

A ontologia proposta por Greller \& Drachsler (2012) identifica seis atividades centrais como críticas para garantir o uso efetivo de LA: competências, limitações (privacidade / ética), tecnologias, dados educacionais, objetivos, stakeholders.

O Organizational Capacity Analytics Framework (Norris \& Baer, 2013) considera as seguintes dimensões como fatores críticos de capacidade organizacional para adoção de LA: infraestrutura tecnológica, processos e práticas, cultura e comportamentos, competências e valores, liderança.

O Learning Analytics Readiness Instrument (LARI) (Arnold et al., 2014) foi desenvolvido para auxiliar instituições a avaliarem se estão prontas para implementar LA, considerando cinco dimensões consideradas essenciais para estabelecer um ambiente propício ao sucesso da implantação de LA: habilidade, dados, cultura / processo, governança / infraestrutura e percepção sobre aptidão.

Para indicar direções para adoção sistêmica de LA, Gašević et al. (2019) baseiamse no modelo organizacional de Barton \& Court (2012), que possui três elementos: dados, modelo e transformação. A partir destes elementos, Gašević et al. (2019) propõem questões específicas ao contexto educacional e à adoção de LA. Em relação aos dados, os autores argumentam que é preciso considerar: criatividade nos processos de coleta de 
dados (considerando fontes variadas, como por exemplo redes sociais); limitações dos dados; e suporte técnico. Em relação ao modelo, os autores destacam o papel das técnicas de aprendizagem de máquina em LA, e argumentam que as aplicações de aprendizagem de máquina devem seguir uma abordagem orientada a perguntas e baseada em pesquisa e prática educacional. Por fim, a transformação envolve a adoção sistêmica de LA para abordar prioridades institucionais que são chave. Para isso, apresentam cinco dimensões críticas: construção de política institucional e estratégia para LA; estabelecimento de modelos de liderança efetiva para guiar a implementação de LA; definição de princípios para proteção da privacidade e uso ético de LA; implementação de ferramentas de LA que atendam as necessidades dos stakeholders; e desenvolvimento de uma cultura de tomada de decisão baseada em analíticas.

Um outro modelo que já foi usado como instrumento para adoção de LA em IES (Ferguson et al., 2014; Macfadyen et al., 2014) é o ROMA (Rapid Outcome Mapping Approach). Este modelo tem como propósito apoiar o desenvolvimento de políticas baseado em evidências, com envolvimento dos stakeholders. O modelo foi inicialmente concebido pelo Overseas Development Institute (ODI) no contexto de políticas de desenvolvimento internacional (Young \& Mendizabel, 2009). O ROMA possui as seguintes seis dimensões: (i) mapear o contexto político; (ii) identificar os stakeholders-chave; (iii) identificar mudanças de comportamento desejadas; (iv) desenvolver estratégias de engajamento; (v) analisar capacidade interna para gerar mudança; e (vi) estabelecer frameworks de monitoramento e aprendizagem.

No contexto do projeto europeu SHEILA (Supporting Higher Education to Integrate Learning Analytics) (Tsai et al., 2018), foi proposto um framework, baseado no modelo ROMA, que considera fatores-chave das instituições de ensino para a adoção de LA. A partir da experiência de adoção de LA em mais de 50 IES europeias, e considerando as perspectivas de estudantes, professores, gestores e especialistas em LA, Tsai et al. (2018) propõem, no framework SHEILA, uma extensão do ROMA adicionando três elementos: ações, desafios e políticas (enquadrados nas dimensões do ROMA).

O SHEILA foi usado como base para o desenvolvimento de framework adaptado aos contextos latino-americanos, no projeto LALA - Learning Analytics in Latin America, e foi também utilizado em um estudo de caso na Universidade Federal Rural de Pernambuco (UFRPE), apresentado neste capítulo, na seção 1.5.3. Assim, na próxima seção, o SHEILA é detalhado em termos de dimensões e instrumentos.

A Tabela 4.2 sumariza os modelos apresentados nesta seção e suas respectivas dimensões.

\subsubsection{Framework SHEILA}

No framework SHEILA (Figura 4.1), Tsai et al. (2018) fazem uma instanciação e relação das dimensões do ROMA com contextos de adoção de LA, da seguinte maneira:

1. Mapear o contexto político: identificar o propósito para adoção de LA;

2. Identificar os stakeholders-chave: guiada pelo reconhecimento de que a implementação de LA envolve esforços coletivos; 
3. Identificar mudanças de comportamento desejadas: definição de objetivos relacionados ao propósito em (1);

4. Desenvolver estratégias de engajamento: abordagens para atingir os objetivos, considerando aspectos que são potenciais desafios, como recursos, ética e privacidade de dados, e envolvimento dos stakeholders;

5. Analisar capacidade interna para gerar mudança: avaliar a disponibilidade de recursos existentes (como dados e investimento financeiro) e identificar riscos;

6. Estabelecer frameworks de monitoramento e aprendizagem: definir indicadores de sucesso de adoção de LA e como medi-los.

Tabela 4.2. Modelos para adoção de LA

\begin{tabular}{l|l}
\hline Modelo & Dimensões \\
\hline $\begin{array}{l}\text { Analytics Maturity Index for Higher Education } \\
\text { (Bichsel, 2012) }\end{array}$ & $\begin{array}{l}\text { cultura, processo, dados / ferramentas, investi- } \\
\text { mento, expertise e governança / infraestrutura }\end{array}$ \\
\hline Ontologia (Greller \& Drachsler, 2012) & $\begin{array}{l}\text { competências, limitações (privacidade / ética), } \\
\text { tecnologias, dados educacionais, objetivos, sta- } \\
\text { keholders }\end{array}$ \\
\hline $\begin{array}{l}\text { Organizational Capacity Analytics Framework } \\
\text { (Norris \& Baer, 2013) }\end{array}$ & $\begin{array}{l}\text { infraestrutura tecnológica, processos e práticas, } \\
\text { cultura e comportamentos, competências e va- } \\
\text { lores, liderança }\end{array}$ \\
\hline $\begin{array}{l}\text { Learning Analytics Readiness Instrument } \\
\text { LARI (Arnold et al., 2014) }\end{array}$ & $\begin{array}{l}\text { habilidade, dados, cultura / processo, gover- } \\
\text { nança / infraestrutura, e percepção sobre apti- } \\
\text { dão }\end{array}$ \\
\hline $\begin{array}{l}\text { Gašević et al. (2019) com base no modelo orga- } \\
\text { nizacional de Barton \& Court (2012) }\end{array}$ & $\begin{array}{l}\text { dados (coleta, limitações e suporte técnico); } \\
\text { modelo (aprendizagem de máquina orientadas } \\
\text { por pesquisa educacional); transformação (polí- } \\
\text { tica institucional; liderança, privacidade e ética; } \\
\text { ferramentas, cultura) }\end{array}$ \\
\hline $\begin{array}{l}\text { Rapid Outcome Mapping Approach - ROMA } \\
\text { (Young \& Mendizabel, 2009) }\end{array}$ & $\begin{array}{l}\text { contexto; stakeholders; mudanças de compor- } \\
\text { tamento desejadas; estratégias de engajamento; } \\
\text { capacidade interna para gerar mudança; fra- } \\
\text { meworks de monitoramento }\end{array}$ \\
\hline $\begin{array}{l}\text { Supporting Higher Education to Integrate Lear- } \\
\text { ning Analytics - SHEILA (Tsai et al., 2018) }\end{array}$ & $\begin{array}{l}\text { extensão do ROMA, considerando: ações, de- } \\
\text { safios e políticas }\end{array}$ \\
\hline
\end{tabular}

O intuito do SHEILA é ser um arcabouço que possa ser instanciado a qualquer IES (embora, naturalmente, seja fortemente baseado no contexto europeu), podendo ser usado no planejamento estratégico das instituições e no desenvolvimento de políticas acadêmicas. Desenvolvido a partir de uma abordagem centrada no humano e guiada pelo contexto, o SHEILA propõe o envolvimento direto de usuários finais de LA para o levantamento de demandas e necessidades, a partir de suas perspectivas, expectativas e preocupações (Tsai et al., 2018). Para isso, o SHEILA propõe a realização de pesquisa de campo na instituição, com os stakeholders, usando como instrumentos: grupos focais, entrevistas e questionários. 


\section{Grupos focais}

Os grupos focais são realizados com estudantes e com professores (separadamente). O roteiro do grupo focal com os estudantes é guiado pelos seguintes temas:

- transparência no uso de dados pela IES, coletados dos ambientes virtuais;

- propósitos legítimos para a IES fazer uso dos dados dos estudantes;

- consentimento para uso dos dados, questões éticas e legais;

- autonomia para aderir ou desistir do consentimento a qualquer momento;

- necessidades educacionais (mecanismos de apoio à aprendizagem fornecidos pela IES);

- feedback dos professores;

- intervenções dos professores a partir da análise dos dados dos estudantes;

- preocupações acerca do uso dos dados pela IES;

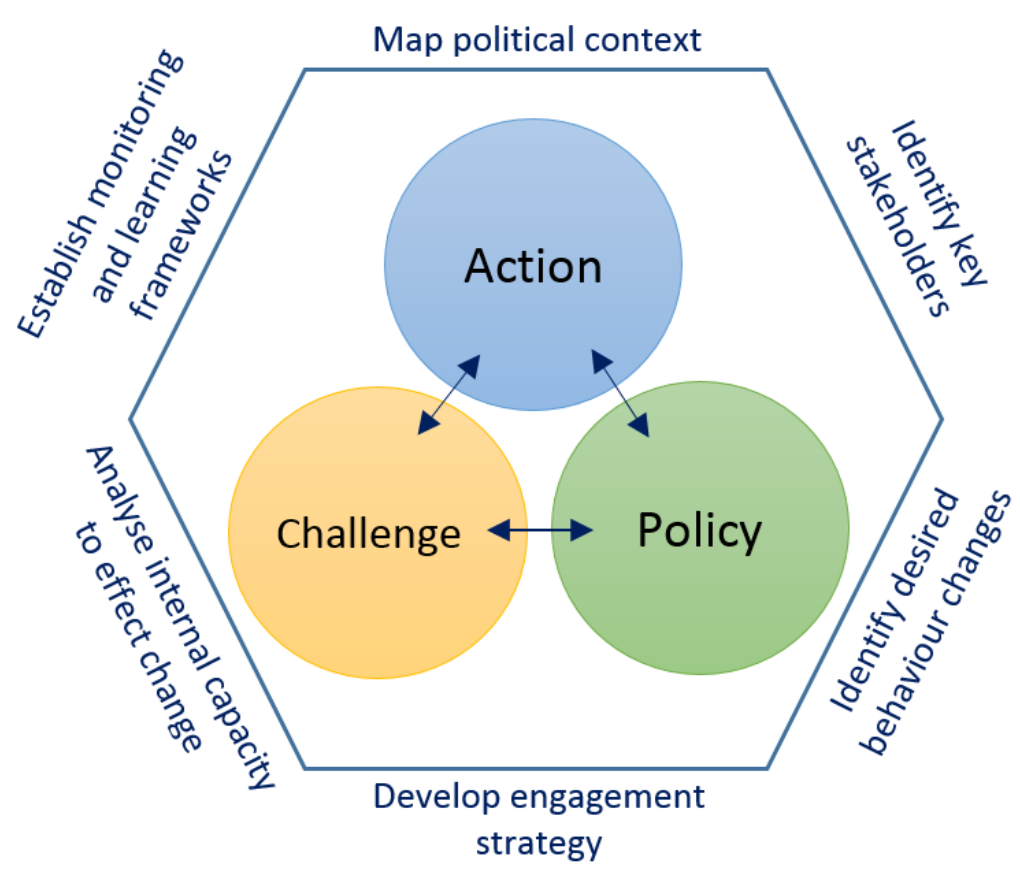

Figura 4.1. Framework SHEILA com as dimensões do ROMA. Fonte: (Tsai et al., 2018)

Os grupos focais com professores abordam temas semelhantes, sendo que do ponto de vista docente:

- propósito legítimos para a IES fazer uso dos dados dos estudantes e/ou dos professores (i.e. relacionados às atividades de ensino); 
- necessidades de ensino (tipos de dados que seriam úteis, desafios e riscos associados ao uso de LA, feedback, apresentação dos dados, disponibilidade para integrar LA em sua prática docente, entre outros);

- ética e privacidade no uso dos dados dos estudantes e das práticas de ensino;

- suporte educacional (formas como LA poderia melhorar o suporte que a universidade provê aos estudantes);

- intervenções dos professores a partir da análise dos dados dos estudantes;

- preocupações acerca da incorporação de LA no processo de ensino;

\section{Entrevistas}

As entrevistas individuais são realizadas com membros da gestão acadêmica, com o objetivo de compreender o contexto da IES e mapear interesses institucionais. No caso de instituições que já possuem um projeto de LA (em andamento ou planejado), a entrevista aborda: os motivos para o uso de LA; as estratégias de e preparação para implantação; se já foram atingidas metas e como os resultados são avaliados; o que contribui ou pode contribuir para o sucesso do projeto; que desafios foram encontrados ou são previstos; quais aspectos éticos e de privacidade precisam ser levados em consideração; e o que é essencial em uma política de LA.

Para IES que não possuem projetos de LA, a entrevista versa sobre: as formas existentes na IES de coleta de dados de estudantes; o motivo e estratégia para coletar os dados; as questões de ética e privacidade; o potencial de uso de LA neste contexto; o motivo de ainda não tem implantado LA; o que seria necessário para fazê-lo; e o que seria essencial em uma política de LA.

\section{Questionários}

O objetivo dos questionários é obter uma visão mais geral da IES, visto que são amplamente distribuídos à comunidade de professores e estudantes, com o objetivo de atingir o maior número possível de pessoas, o que é inviável com o uso dos métodos de pesquisa qualitativa (grupos focais e entrevistas).

Os questionários analisam a expectativa desses dois grupos acerca das possibilidades, usos e benefícios de LA, com base em duas visões: para cada item do questionário, o respondente deve classificar, em uma escala Likert, (i) o quão desejável aquele item é, em sua opinião; (ii) e o quão factível aquele item é, considerando a realidade da instituição.

Os itens dos questionários abordam os mesmos temas discutidos nos grupos focais, porém com afirmações mais detalhadas, como, por exemplo, no caso dos estudantes: "o serviço de análise de dados mostrará como meu progressos acadêmico está relacionado aos meus objetivos de aprendizagem e aos objetivos da disciplina"; "A universidade solicitará meu consentimento para coletar, usar e analisar qualquer um dos meus dados educacionais (por exemplo, notas, participação em aulas e acessos no ambiente virtual de aprendizagem)". Exemplos dos itens do questionário aos professores incluem: "A universidade me fornecerá orientações sobre como ter acesso a visualização dos resultados de aprendizagem dos meus alunos."; e "O corpo docente tem obrigação de agir (apoiando 
os alunos) se as análises mostrarem que um aluno está em risco de reprovação ou que ele pode melhorar seu aprendizado.".

\subsubsection{Estudo de caso na UFRPE}

No Brasil, assim como na América Latina, a adoção de LA ainda é incipiente, quando comparada com contextos europeus e norte-americanos. Embora a área esteja crescendo em termos de pesquisa (Cechinel et al., 2020), ainda são poucas as implementações consolidadas de técnicas de LA nas IES.

Na Universidade Federal Rural de Pernambuco (UFRPE), o interesse por um uso sistemático e automatizado dos dados educacionais, em prol da melhoria do processo de ensino-aprendizagem, tem crescido. Entretanto, a instituição ainda enfrenta muitos desafios relacionados a como estabelecer um ambiente tecnológico e organizacional que permita um uso efetivo e seguro dos dados, assim como muitas outras universidades públicas brasileiras.

Nesse contexto, foi realizado um estudo de campo (Falcao et al., 2019; Pontual Falcão, Mello, et al., 2020) utilizando-se os instrumentos de análise do contexto do framework SHEILA, para mapear as dimensões consideradas fundamentais para a implantação de LA e propor direções à gestão da IES. Participaram 17 professores, 4 tutores e 22 estudantes da UFRPE, das modalidades presencial e a distância. No total, foram realizados sete grupos focais e 5 entrevistas individuais. Os instrumentos do SHEILA foram traduzidos e levemente adaptados ao contexto da educação superior pública brasileira, e foram realizadas algumas entrevistas individuais (com o mesmo roteiro dos grupos focais) por limitações operacionais. Os resultados apresentados a seguir podem ser considerados por outras IES brasileiras interessadas em implantar LA.

\section{Perspectivas dos estudantes}

O tópico de necessidades educacionais foi o mais debatido pelos estudantes. Em particular, foram relatadas muitas dificuldades relacionadas à usabilidade dos ambientes virtuais de aprendizagem, como: dificuldade de aprender a usar o AVA; e organização das informações no ambiente (dificuldade de acompanhar discussões em fóruns e identificar / gerenciar mensagens privadas). Foi relatada também a dificuldade de comunicação com professores, incluindo a formalidade e ineficácia de envio de mensagens via AVA, e o medo de exposição ao participar de fóruns. Os estudantes avaliaram os recursos didáticos disponibilizados como pouco diversos e precisando de revisões e atualizações (principalmente as apostilas e livros). Os estudantes também opinaram que deveria haver maior flexibilidade nos cursos para levar em consideração as condições socioeconômicas, incluindo as condições de acesso a Internet e computadores. Por fim, sobre possíveis usos dos seus dados, os estudantes gostariam ter com retorno, principalmente, uma visualização de seu perfil de aprendizagem em cada módulo e guiá-los em caminhos de aprendizagem ideais.

Sobre o propósito para a IES usar LA, os estudantes veem como principais benefícios: melhorar a experiência de aprendizagem (usando estatísticas como notas e índices de evasão, analisando aspectos que contribuem para baixo desempenho, e criando soluções). Também foi sugerido usar LA para identificar os métodos pedagógicos e recursos 
educacionais mais adequados a cada disciplina, com base no desempenho médio dos estudantes.

Em relação a feedback, os estudantes destacaram que apenas notas não são suficientes, e que são necessárias informações sobre os erros e acertos. Este feedback precisa ser dado a tempo de se retrabalhar as atividades avaliativas, de forma personalizada e iterativa, para que seja produtivo no processo de ensino-aprendizagem. O tema de transparência e consentimento não gerou grande discussão. Percebe-se que a boa reputação da universidade e a natureza dos dados educacionais, dentro do contexto de um processo de ensino-aprendizagem, leva os estudantes a confiarem que seus dados serão utilizados de forma restrita à IES e exclusivamente para questões educacionais.

\section{Perspectivas dos instrutores}

Da parte dos instrutores (ou seja, professores e tutores da EAD), acerca do propósito do uso de dados, foram mencionados, entre outros: reduzir a evasão; melhorar sua prática docente e a aprendizagem dos estudantes; e estabelecer boas práticas institucionais.

Sobre necessidades de ensino, os instrutores gostariam de ter maior visibilidade do progresso e dificuldades dos estudantes. Atualmente, embora os dados existam, o acesso e interpretação são complexos. Os tipos de dados citados incluíram os dados mais comuns (como acesso dos estudantes ao ambiente - tempo e frequência, número de downloads do material de estudo; e dados demográficos e socioeconômicos); mas também questões mais específicas como o tipo de material mais acessado; tempo de leitura de um texto; qualidade de produção textual; trajetória acadêmica do estudante; desempenho do estudante por área do conhecimento, entre outros. Existe grande interesse dos instrutores em saber a efetividade das atividades de ensino, que poderia ser analisada a partir do comportamento dos estudantes. Ou seja, os instrutores gostariam de poder ir além de dados objetivos como número de downloads, para compreender se os estudantes estão de fato aprendendo a partir das atividades propostas. Outro tópico de grande interesse é como despertar e manter a motivação dos estudantes.

Foi também comentada a necessidade de uma interface de visualização de dados que seja simples, objetiva e customizável, explorando diversas representações como gráficos e nuvens de palavras. Os instrutores gostariam de poder identificar facilmente, a partir de tais visualizações, que estudantes estão em risco de reprovação ou evasão, e que ações deveriam ser tomadas (inclusive recebendo recomendações do sistema com sugestões de atividades para aquele estudante, por exemplo).

Em relação ao tema de ética e privacidade, os instrutores demonstraram preocupação em relação a uma excesso de intromissão e controle da rotina de estudo dos alunos, o que pode levar a desconforto. Foi destacada a necessidade de um certo espaço privado ser respeitado. Os instrutores também demonstraram preocupação com sua própria privacidade, temendo excesso de controle institucional e até mesmo por parte do governo federal, ameaçando a autonomia docente.

Os instrutores concordam que têm a obrigação de agir ao identificar dificuldades de aprendizagem. Entretanto, a introdução sistemática de LA pode levar a grandes mudanças que exijam tempo e aprendizado dos instrutores, o que também é uma preocu- 
pação. Os instrutores concordam que a IES deve fornecer formações aos instrutores em particular para análise dos dados recebidos.

Uma outra preocupação mencionada refere-se a como os instrutores receberão eventuais feedbacks negativos, e a resistência a sair da sua zona de conforto. Além disso, em particular a nível institucional, é preciso tomar muito cuidado para não tomar decisões precipitadas ou chegar a conclusões descontextualizadas, com base em uma determinada visão sobre os dados. O uso responsável e razoável dos dados foi destacado pelos instrutores.

\section{Desdobramentos}

A partir das perspectivas e necessidades apresentadas pelos stakeholders, podem ser visualizados algumas possíveis aplicações de LA em IES com contextos similares ao da UFRPE, ou seja, do ensino superior público brasileiro (Pontual Falcão, Mello, et al., 2020). Tais aplicações são listadas a seguir:

- Interfaces adaptativas no AVA que se adequem ao nível de experiência do usuário;

- Dashboards para auxiliar estudantes a visualizarem seu progresso e assim organizar melhor seus estudos e objetivos de aprendizagem;

- Ferramentas de navegação em fóruns para facilitar discussões online;

- Conteúdo personalizado com base no histórico do estudante;

- Ferramentas de apoio para geração de feedback personalizado e humanizado em larga escala;

- Predição de evasão.

A seção seguinte mostra dois exemplos de ferramentas que já são usadas em IES e que se encaixam em alguns desses itens.

\subsection{Exemplos de Ferramentas de LA}

Esta seção tem o objetivo de apresentar duas ferramentas de LA que vêm sendo utilizadas por instituições da América Latina. Como não faz parte do escopo do curso a discussão sobre o código das ferramentas, serão apresentados, então, seus objetivos, funcionamento e exemplos de telas que expõem a sua utilização.

\subsubsection{Feedback personalizado}

O feedback é uma parte crucial da comunicação entre alunos e professores em termos de esclarecer expectativas, monitorar o progresso dos alunos e ajudá-los a alcançar as metas de aprendizado desejadas (Hattie \& Timperley, 2007). No entanto, existem evidências substanciais que mostram que, principalmente no ensino superior, é um grande desafio fornecer feedback consistente, oportuno e construtivo para atender às necessidades e expectativas dos alunos (Boud \& Molloy, 2013). Um dos problemas para envio de feedback é a grande quantidade de alunos e atividades que os professores costumam ter todo semestre (Pardo, 2018). 
Nesse contexto, a ferramenta OnTask propõe uma interface para auxiliar professores a fornecer feedback rápido e personalizado aos alunos (Pardo et al., 2019). A OnTask utiliza Learning Analytics para personalizar, semi-automaticamente, mensagens que são construídas no formato de "se ... então"para ajudar os professores a compor feedback personalizado para uma grande quantidade de alunos com base em parâmetros relevantes para o design do curso (Pardo et al., 2019).

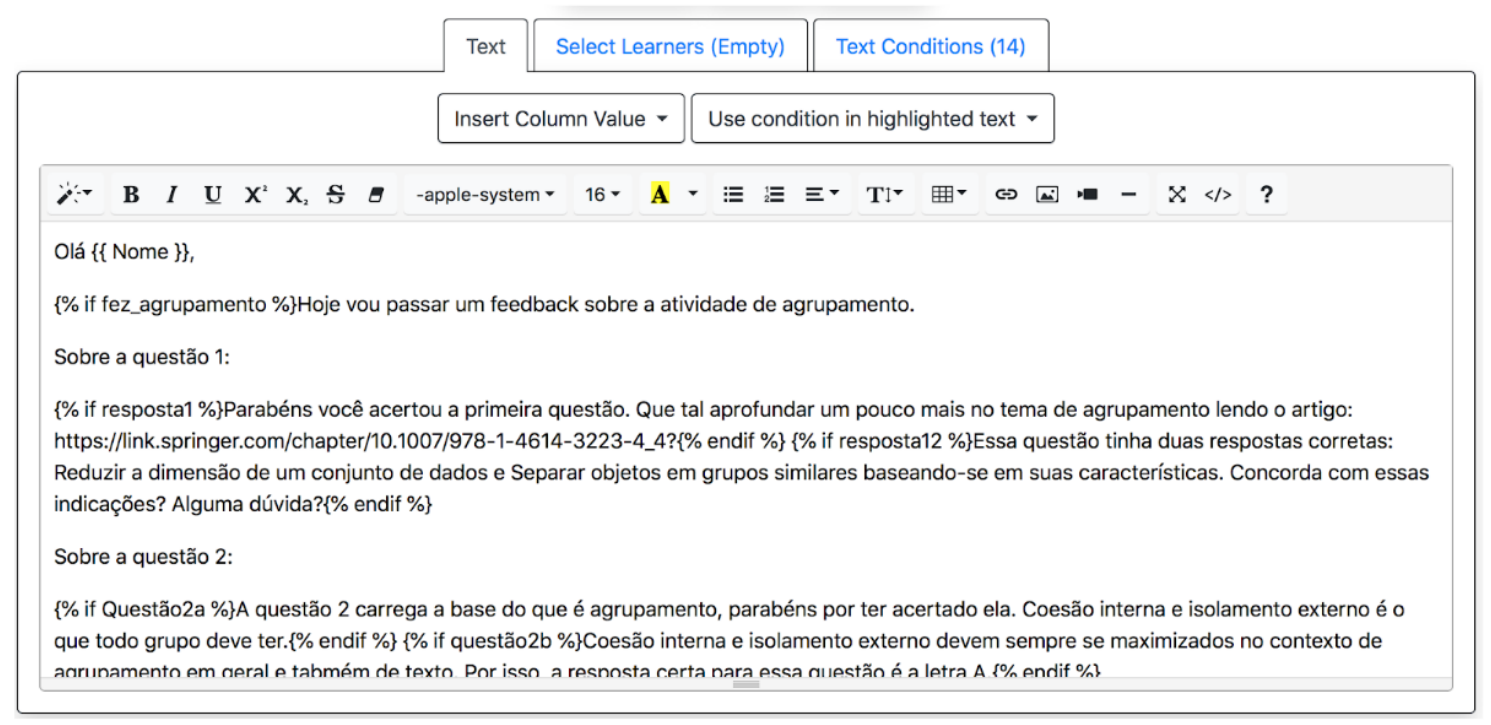

Figura 4.2. Tela para escrita de email (autores).

A Figura 4.2 mostra a interface que o professor usa para compor os e-mails personalizados. É possível ver que no texto do feedback existem atributos que são personalizáveis e regras "se ... então". Por exemplo, o atributo Nome vai recuperar do banco de dados o nome dos alunos e incluí-lo na mensagem final. Além disso, na segunda linha de texto existe uma regra (iffez_agrupamento) que verifica se um determinado aluno concluiu ou não a atividade para a qual o feedback está sendo enviado. Ademais, é possível filtrar os alunos que vão receber o feedback e criar novas regras para a mensagem através dos recursos Select Learners e Text Conditions, no menu de cima da figura.

A Figura 4.3 apresenta dois exemplos de mensagens personalizadas que foram criadas. Este exemplo envia um feedback para o aluno que respondeu a atividade. Esta mensagem contém informações personalizadas ${ }^{2}$ para alunos específicos. Já a mensagem apresentada na Figura 4.4 é referente a um aluno que não realizou a atividade. É importante destacar que o sistema personaliza a mensagem mas é o professor que cria as regras de personalização.

Durante o curso, apresentaremos ainda os resultados da análise inicial da execução piloto do OnTask em cenário real, realizada durante uma disciplina de graduação na Universidade Federal Rural de Pernambuco.

\footnotetext{
${ }^{2} \mathrm{O}$ nome foi excluído por questões de privacidade.
} 


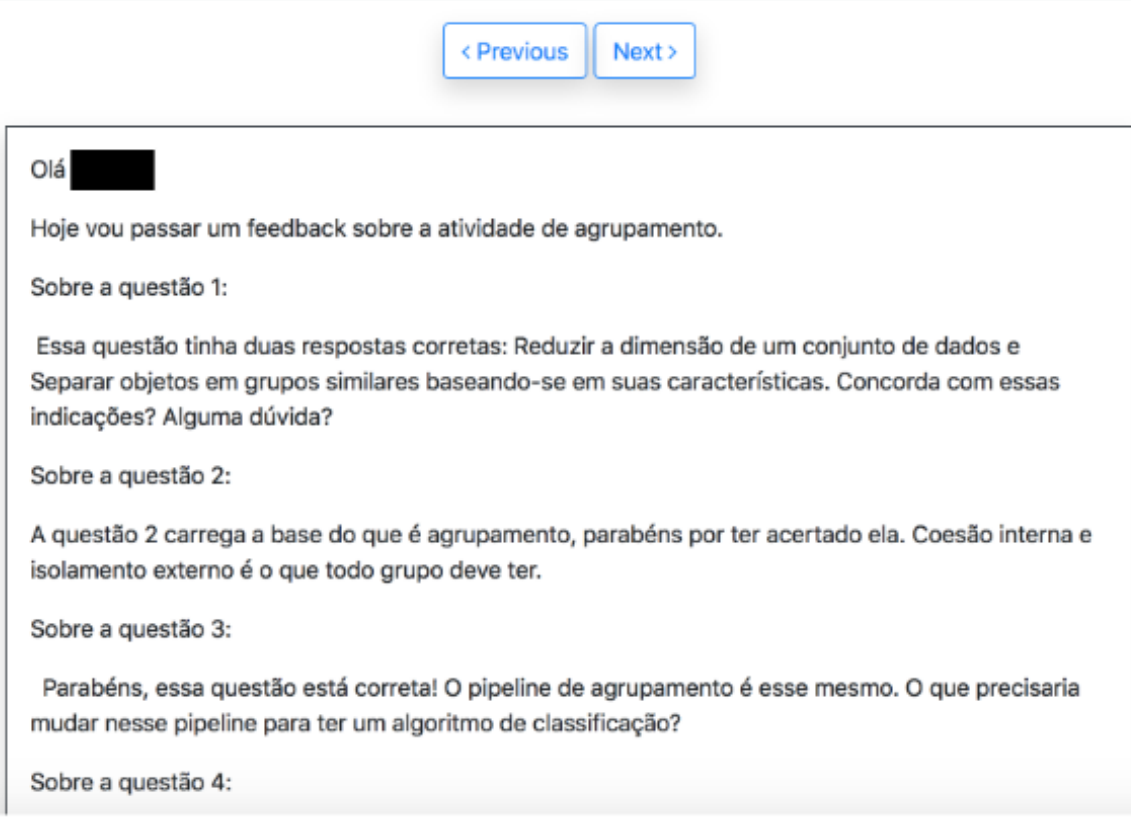

Figura 4.3. Exemplos de mensagem completa de feedback (autores).

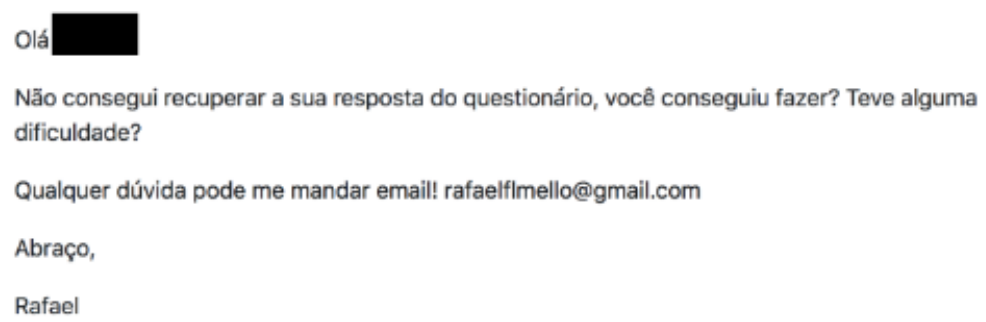

Figura 4.4. Exemplos de mensagens para aluno que não realizou a atividade (autores).

\subsubsection{Auxílio a matrícula}

Um questionamento constante de instituições de ensino que desejam usar LA é relacionado à relevância dos dados. Muitas instituições deixam de utilizar ferramentas para análise de dados educacionais por achar que não possuem ou não armazenam dados relevantes. Contudo, vários trabalhos mostram que com apenas dados relacionados a notas e presenças dos alunos já é possível utilizar ferramentas de LA e melhorar algum aspecto educacional da instituição (De Laet et al., 2020; Gutiérrez et al., 2020). 
Por exemplo, as ferramentas propostas pelo projeto LALA ${ }^{3}$ têm como objetivo utilizar os dados mais simples possíveis para facilitar a adoção dessas ferramentas por universidades da América Latina, principalmente focando nas que não têm tanta experiência na utilização desse tipo de ferramenta.

Ao mesmo tempo, algumas das principais dificuldades encontradas no contexto brasileiro e da América Latina são a evasão e a retenção. A Figura 4.5 apresenta uma interface estilo dashboard, com informações relevantes para a tomada de decisão relacionada à matrícula de alunos. É importante frisar que esse sistema foi desenvolvido para ser usado por professores e não por alunos.

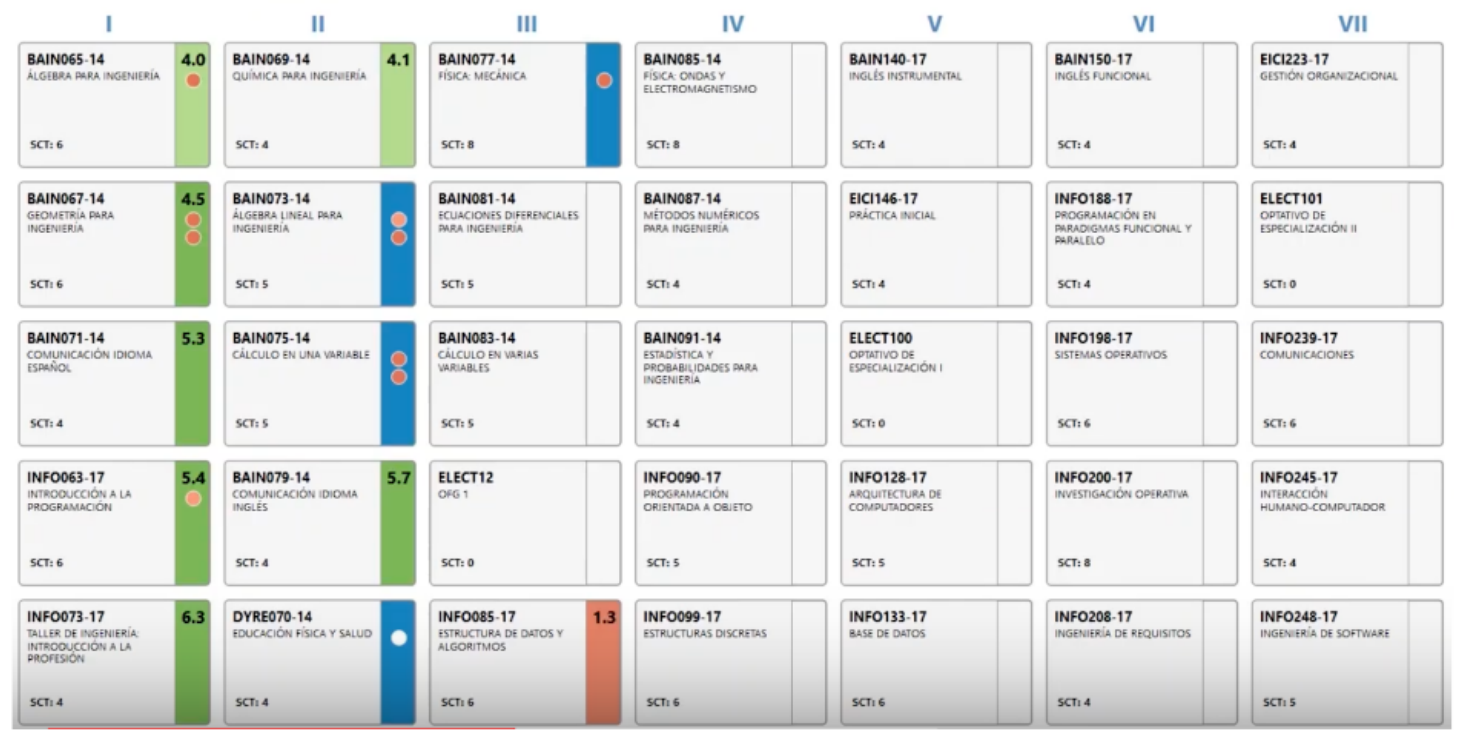

Figura 4.5. Dashboard para auxílio na matrícula de alunos ${ }^{5}$

Essa visualização apresenta as informações específicas para um aluno que está sendo analisado. Na figura 4.5 existem várias informações:

- As disciplinas destacadas em verde são as que já foram cursadas pelo aluno e ele foi aprovado.

- As disciplinas em azul são as que estão sendo cursadas no momento pelo aluno.

- As disciplinas em vermelho são aquelas em que o aluno já foi reprovado.

- As disciplinas em cinza são as disciplinas da matriz curricular do curso que o aluno ainda não cursou nem está cursando.

Além destas informações, os pequenos círculos dispostos em cada disciplina representam a quantidade de vezes que o aluno reprovou naquela disciplina em específico. Por fim, o número que aparece é a nota do aluno em questão nas disciplinas que ele já cursou.

\footnotetext{
${ }^{3}$ https://git.cti.espol.edu.ec/LALA-Project-EN
} 
O principal objetivo dessa ferramenta é auxiliar coordenadores de curso ou professores responsáveis por aconselhamento de alunos no processo de sugestão da matrícula. Este sistema é especialmente importante para alunos que correm algum risco de desligamento do curso.

Apesar dessa ferramenta não ter um objetivo preditivo ou de recomendação direta para os alunos, existem estudos em andamento para avaliar a qualidade da recomendação automática de disciplinas que aumentam a probabilidade de aprovação do aluno (Guerra et al., 2020). Contudo, esse tipo de recomendação ainda precisa ser analisada com mais detalhes, pois sugestões deste tipo diretamente para o aluno podem causar um efeito negativo se não forem bem avaliadas (Gašević et al., 2015).

\subsection{Monitoramento: $O$ papel do Modelo de Maturidade para Adoção de $L e$ - arning Analytics}

Uma vez que a instituição de ensino está a par do seu contexto e das ferramentas que podem ser utilizadas para dar início ao processo de adoção de LA, é necessário, então, entender quais áreas merecem maior atenção nesse processo de adoção. Além disso, é essencial monitorar o progresso a fim de que a instituição possa evoluir gradativamente na utilização de LA. Para isso, é necessário alcançar um maior número de stakeholders e preparar-se para lidar com outros temas, relacionados, por exemplo, à gestão de dados, à governança e capacitação da equipe e dos estudantes, questões pedagógicas, entre outros (Tsai et al., 2018).

Um instrumento que pode apoiar o monitoramento e a evolução na adoção de LA é o MMALA (Modelo de Maturidade para Adoção de Learning Analytics). Segundo E. Freitas et al. (2020), um Modelo de Maturidade (MM) funciona como um roteiro que identifica as atividades-chave que ajudam a instituição a alcançar níveis mais altos de maturidade em uma determinada área. Nesse caso, o MMALA identifica as áreas críticas a serem consideradas na adoção de LA bem como as atividades que podem ser realizadas em cada uma dessas áreas, indicando um caminho de melhoria em quatro níveis de maturidade e permitindo o monitoramento do progresso da instituição de ensino em cada uma dessas áreas. A utilização do MMALA pode permitir às instituições empregar LA de modo planejado e sistemático, atendendo às necessidades específicas de cada uma delas ao propor níveis de maturidade convenientes, os quais permitem identificar a situação atual da instituição e ascender a níveis mais altos de maturidade gradativamente.

O MMALA foi avaliado por 13 especialistas na área de LA, de diferentes países, e foi considerado abrangente para apoiar as instituições nos desafios relacionados à adoção de LA; consistente, isto é, a descrição dos elementos do modelo foi considerada coerente em cada área de processo; e também foi avaliado como adequado ao seu propósito de apoiar a adoção de LA.

\subsubsection{Descrição do MMALA}

O MMALA é constituído de 16 Áreas de Processos voltadas para uma adoção planejada e sistemática de LA, as quais estão organizadas em 5 categorias. Uma área de processo comunica os objetivos e define as práticas recomendadas para aquela área a fim de que a organização alcance maturidade (DMM, 2014). A Tabela 4.3 apresenta os detalhes sobre 
cada categoria e área de processo do modelo.

\begin{tabular}{c|l}
\hline \multicolumn{1}{c|}{ Categorias } & Áreas de Processos \\
\hline \multirow{3}{*}{ Gestão dos Dados } & Aquisição de Dados (DA) \\
& Qualidade de Dados (DQ) \\
& Propriedade dos dados (DO) \\
& Infraestrutura (INF) \\
\hline \multirow{3}{*}{ Governança e Capacitação } & Financiamento (FUN) \\
& Liderança (LEA) \\
& Identificação e envolvimento dos stakeholders(SII) \\
& Comunicação (COM) \\
& Capacitação dos stakeholders (STR) \\
\hline \multirow{3}{*}{ Apoio Pedagógico } & Planejamento pedagógico das soluções (PPS) \\
& Apoio na interpretação dos resultados (SIR) \\
& Intervenção Baseada nos Resultados (RBI) \\
\hline \multirow{3}{*}{ Análise de Dados } & Desenvolvimento de soluções próprias (DOS) \\
& Aquisição de soluções prontas (ACQ) \\
& Avaliação da eficácia das soluções (EVA) \\
\hline Legislação, Privacidade e Ética & Legislação, Privacidade e Ética (LPE) \\
\hline
\end{tabular}

Tabela 4.3. Categorias e áreas de processos do MMALA

A categoria de Gestão dos Dados engloba as práticas necessárias para gerenciamentos dos dados (voltadas para a aquisição, qualidade e propriedade) e da infraestrutura de TI da instituição. Na categoria de Governança e Capacitação, o foco é a gestão da instituição para a liderança e financiamento dos projetos, comunicação dos resultados, além do envolvimento e capacitação dos stakeholders. Na categoria de Apoio Pedagógico, há uma preocupação com o planejamento pedagógico das soluções, além da interpretação dos resultados obtidos e das possíveis intervenções pedagógicas que podem ser realizadas a partir desses resultados. Na categoria de Análise de Dados, as atenções são voltadas para o desenvolvimento ou a aquisição de soluções, além de sua avaliação. Por fim, na categoria de Legislação, Privacidade e Ética, discutem-se as diretrizes para que os projetos de LA sejam legalizados e atendam aos critérios de privacidade e ética no uso de dados.

Quanto aos 4 níveis de maturidade do MMALA, estes são: Ad Hoc, Inicial, Estruturado e Sistemático. Para evoluir de um nível a outro é necessário implementar todas as práticas funcionais descritas para aquele nível na respectiva área de processo. De acordo com E. Freitas et al. (2020), os níveis de maturidade estão divididos da seguinte forma:

- No primeiro nível de maturidade, Ad Hoc, os processos de adoção de Learning Analytics não estão estabelecidos, ocorrendo de modo desordenado. As atividades são realizadas sem planejamento prévio ou abrangente a toda instituição, e envolve poucos pesquisadores e estudantes;

- No Nível 2, Inicial, os processos começam a se formalizar, favorecendo a ampliação da utilização de LA na instituição. Cada projeto define seus próprios objetivos 
e critérios para implementação e avaliação das ferramentas. Pode-se citar como benefícios esperados para as instituições que atingem esse nível de maturidade: (a) maior abrangência dos projetos de LA, o que resulta em maior quantidade de usuários, sendo esses alunos e professores, e também de dados para análise, podendo gerar soluções mais maduras; (b) as ferramentas passam a ser avaliadas, permitindo ajustes e maior personalização das mesmas para atender a usuários de diferentes cursos; (c) maior engajamento e, consequentemente, maior compreensão sobre o papel de LA para o ensino e aprendizagem em diferentes departamentos da instituição; e (d) os projetos de LA atendem aos regulamentos definidos pela instituição no que se refere à ética e à privacidade;

- No Nível 3, Estruturado, a instituição reconhece e dá suporte à adoção de Learning Analytics, de modo que os processos são formalmente estabelecidos e as responsabilidades de cada stakeholder são definidas. O planejamento dos projetos de LA estão alinhados aos objetivos estratégicos da instituição. Os benefícios esperados nesse nível são: (a) o estabelecimento de uma liderança formal leva à execução coordenada de projetos, com processos melhor definidos, trazendo maior organização e aumentando a probabilidade de sucesso dos mesmos; (b) há uma maior atenção à infraestrutura para dar suporte às soluções de LA, com investimentos em sua evolução; e (c) o alinhamento das soluções ao objetivo da instituição ajuda a reforçar o compromisso da alta gerência com o patrocínio e com o sucesso dos projetos;

- Por fim, no último nível de maturidade, Sistemático, há processos e políticas formalmente estabelecidos e seguidos, de modo que a adoção de LA se torna abrangente a toda instituição, sendo planejada e executada sistematicamente. Entre os benefícios de atingir esse nível de maturidade, destacam-se: (a) as soluções podem ser enriquecidas pelo conhecimento de profissionais de diferentes áreas de conhecimento, atendendo de forma cada vez mais eficaz os objetivos da instituição e de stakeholders estratégicos; (b) a instituição passa a adotar uma política institucional, válida para todos os projetos de LA, a fim de atender às questões éticas e legais sobre o uso de dados dos estudantes; (c) LA se torna parte da cultura da organização, havendo inclusive um Programa de Financiamento para LA, havendo recursos específicos para os projetos em execução e para novos projetos; e (d) a instituição tem processos, pessoas e objetivos definidos para a utilização de LA.

A Figura 4.6 exibe os níveis de maturidade do MMALA, descrevendo-os brevemente.

Em cada uma das áreas de processos, há uma descrição completa de seu propósito e objetivos, das áreas de processos relacionadas e das suas práticas funcionais - isto é, as atividades que devem ser executadas para aprimorar a utilização de LA na instituição, as quais estão divididas em 4 níveis de maturidade, cuja complexidade aumenta gradativamente. A execução das práticas funcionais permite atingir os objetivos descritos naquela área. Em cada um dos níveis são descritos também os exemplos de produto de trabalho resultantes da institucionalização do respectivo nível de maturidade. Esses produtos de trabalho podem ser, por exemplo, a definição de um processo ou política, um documento, um código, entre outros. 


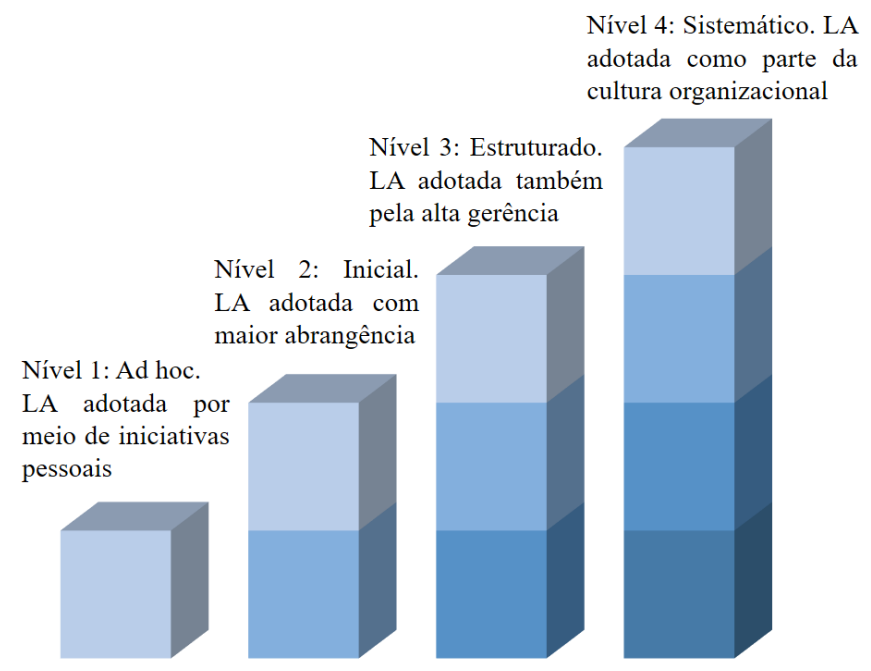

Figura 4.6. Níveis de Maturidade do MMALA.

A Figura 4.7 mostra um exemplo de Área de Processo do MMALA, nesse caso, de Propriedade de Dados. É possível verificar que o seu propósito é "especificar a propriedade dos dados utilizados nos projetos de LA". Além disso, há um conjunto de 3 objetivos que podem ser alcançados com a execução das práticas funcionais descritas (estas últimas divididas em 4 níveis de maturidade). Assim, é possível à instituição verificar em qual nível de maturidade ela está no que tange a Propriedade de Dados e também quais ações pode tomar a fim de evoluir gradativamente nessa área.

Para facilitar a compreensão do nível no qual cada prática funcional está descrita, há um esquema de numeração composto pela sigla da Área de Processo seguida por dois números separados por um ponto, os quais funcionam da seguinte forma: o primeiro número se refere ao nível de maturidade e o segundo se refere ao número da prática funcional. Por exemplo, DO1.2 se refere à segunda prática funcional do Nível de Maturidade 1 na Área de Processo de Propriedade de Dados.

\subsubsection{Adoção do Modelo MMALA}

O Modelo de Maturidade para Adoção de Learning Analytics foi concebido para permitir sua utilização de forma flexível e adaptável. Isto é, a instituição pode optar por concentrarse em qualquer combinação de categorias ou áreas de processos (E. Freitas et al., 2020), sendo as áreas de processos relacionadas a um indicativo seguro daquelas áreas em que se recomenda a adoção conjunta. Por exemplo, a instituição pode priorizar inicialmente a categoria de Gestão de Dados e Análise de Dados em sua adoção de LA, ou as áreas de processos de Aquisição de Dados, Financiamento e Aquisição de Soluções Prontas, por exemplo. Apesar da flexibilidade, o modelo permite também que a instituição siga um percurso previamente definido e analisado, caso opte por progredir nível a nível em cada uma das áreas de processos definidas no modelo.

É válido ressaltar, porém, a importância de se considerar as questões de Legislação, Privacidade e Ética na adoção de LA, visto que, quaisquer iniciativas que desconsiderem essa área podem implicar em problemas legais, e estes podem levar ao impedimento 


\begin{tabular}{|c|c|c|c|}
\hline \multicolumn{4}{|c|}{ Ärea de Processo: Propriedade dos Dados } \\
\hline \multicolumn{4}{|c|}{$\begin{array}{l}\text { Objetivos: } \\
\text { 1. Definir critérios a fim de estabelecer os proprietários dos dados gerados pelas ações dos estudantes e professores; } \\
\text { 2. Tornar transparentes quais dados sobre ações acadêmicas dos estudantes e professores são armazenados e como são analisados; e } \\
\text { 3. Tornar acessiveis aos participantes dos projetos os dados sobre os quais têm propriedade. }\end{array}$} \\
\hline \multicolumn{4}{|c|}{ Práticas Funcionais: } \\
\hline $\begin{array}{l}\frac{\text { Nivel 1 }}{\text { DO1.1. }} \\
\text { Não há critérios formalmente } \\
\text { estabelecidos nos projetos de LA } \\
\text { que definam a propriedade sobre } \\
\text { os dados. } \\
\text { DO1.2. } \\
\text { Os estudantes e professores só } \\
\text { conhecem quais dados sobre } \\
\text { suas ações acadêmicas são } \\
\text { armazenados e analisados após } \\
\text { solicitação explícita. }\end{array}$ & $\begin{array}{l}\text { Nivel 2 } \\
\text { DO2.1 } \\
\text { Os estudantes e professores são } \\
\text { consultados sobre a utilizacãa } \\
\text { dos seus dados para os projetos } \\
\text { de LA, podendo autorizá-la ou } \\
\text { não. } \\
\text { DO2.2 O } \\
\text { Para cada projeto, estão } \\
\text { detalhados quais dados serão } \\
\text { analisados a fim de obter o } \\
\text { consentimento dos participantes. } \\
\text { DO2.3 O } \\
\text { Os participantes conhecem } \\
\text { todos os projetos que utilizam } \\
\text { seus dados. }\end{array}$ & $\begin{array}{l}\text { Nivel } 3 \\
\text { DO3.1 } \\
\text { São definidos os critérios que classificam os } \\
\text { dados considerados de propriedade dos } \\
\text { estudantes, da instituição e de outras partes } \\
\text { interessadas, como agências governamentais, } \\
\text { uniforme para todos os projetos de LA. } \\
\text { DO3.2 } \\
\text { Os estudantes e professores conhecem quais } \\
\text { dados sobre suas ações são armazenados e os } \\
\text { propósitos de armazenamento e análise dos } \\
\text { mesmos. } \\
\text { DO3.3 } \\
\text { Estão claros como os dados são analisados } \\
\text { (isto é, como funciona o algoritmo utilizado para } \\
\text { análise), trazendo maior transparência ao } \\
\text { processo de análise de dados. } \\
\text { DO3.4 O } \\
\text { Os proprietários são responsáveis por decidir } \\
\text { questões sobre o uso de seus dados. Isso inclui } \\
\text { a decisão sobre o uso dentro da instituição e o } \\
\text { compartilhamento com terceiros. A exceção } \\
\text { são aqueles dados considerados primordiais } \\
\text { para o gerenciamento acadêmico básico do } \\
\text { aluno. Todas as exceções devem ser } \\
\text { justificadas. }\end{array}$ & $\begin{array}{l}\text { Nivel } 4 \\
\text { DO4.1 } \\
\text { Os usuários podem acessar os dados } \\
\text { sobre os quais têm propriedade. } \\
\text { DO4.2 O } \\
\text { Existe uma política aprovada e seguida } \\
\text { que define a propriedade dos dados e } \\
\text { está alinhada aos objetivos da instituição } \\
\text { e às questões legais e éticas. } \\
\text { Essa política define os critérios de } \\
\text { propriedade, quem tem acesso aos } \\
\text { dados em questão e o ciclo de vida dos } \\
\text { dados, incluindo as ações a serem } \\
\text { tomadas quando o curso acabar. Expõe- } \\
\text { se, também, direitos e responsabilidades } \\
\text { sobre seu uso. }\end{array}$ \\
\hline
\end{tabular}

Figura 4.7. Um exemplo de Área de Processo do MMALA (Propriedade de Dados).

da continuidade dos projetos

\subsubsection{Conclusões sobre uso do MMALA}

A utilização de um MM pode trazer diversos benefícios, os quais podem se estender ao uso do MMALA. Podem-se citar, por exemplo: Uma maior consciência sobre o tópico analisado (seu estado, importância, potenciais, requisitos, complexidade, entre outros). Além disso, eles permitem às organizações implementar uma abordagem sistemática e bem dirigida para melhorias, permitindo garantir certa qualidade, evitar erros e avaliar suas próprias capacidades numa base comparável (Wendler, 2012); Os Modelos de Maturidade podem ainda ajudar as organizações a estabelecer objetivos para a melhoria de processo e identificar oportunidades de otimização (de Soria et al., 2009).

Portanto, o MMALA é um instrumento útil para ajudar na adoção de LA, provendo os recursos necessários para que as instituições tenham consciência das áreas e ações necessárias para iniciar a utilização de LA. Além disso, o MMALA disponibiliza um roteiro que permite às instituições planejar a evolução do uso de LA. Por fim, é possível ainda monitorar o progresso, por meio da verificação dos produtos de trabalho, os quais demonstram que a instituição executou adequadamente um determinado nível de maturidade.

Por fim, o MMALA deve ser utilizado para orientação do processo de adoção de Learning Analytics - de modo que cada instituição pode decidir qual o nível de maturidade mais adequado para o seu contexto. Isso pode significar, por exemplo, que o $4^{\circ}$ nível de maturidade venha a ser considerado muito complexo ou mesmo muito custoso para uma determinada instituição, a qual pode decidir por se estabelecer em um nível de maturidade inferior, mais adequado para o seu contexto e o seu ambiente institucional. 


\subsection{Considerações finais}

Este capítulo teve como principal objetivo apresentar uma visão geral sobre a área de Learning Analytics. Para isso, foram descritos os principais conceitos, instrumentos para adoção e monitoramento, assim como alguns exemplos de ferramentas. É importante destacar que essa área é muito recente e ainda em desenvolvimento muito rápido. Diante deste cenário, este capítulo é um esforço inicial para a divulgação deste campo no Brasil.

Um fato extremamente importante a se considerar é que as ferramentas de LA não são "one size fits all"(Gašević et al., 2016). Por isso, o contexto da instituição deve ser levado em consideração. Neste sentido, trabalhos relacionados ao contexto brasileiro ainda são escassos. Contudo, é possível encontrar material relevante sobre o contexto latinoamericano site do projeto LALA ${ }^{6}$ e na edição especial do British Journal Educational Technology chamada Applications of learning analytics in Latin America (Pontual Falcão, Ferreira Mello, \& Lins Rodrigues, 2020).

\section{Referências}

Arnold, K. E., Lonn, S., \& Pistilli, M. D. (2014). An exercise in institutional reflection: The learning analytics readiness instrument (lari). In Proceedings of the fourth international conference on learning analytics and knowledge (pp. 163-167).

Baneres, D., Caballé, S., \& Clarisó, R. (2016). Towards a learning analytics support for intelligent tutoring systems on mooc platforms. In 2016 10th international conference on complex, intelligent, and software intensive systems (cisis) (p. 103-110).

Barton, D., \& Court, D. (2012). Making advanced analytics work for you. Harvard business review, 90(10), 78-83.

Bichsel, J. (2012). Analytics in higher education: Benefits, barriers, progress, and recommendations. EDUCAUSE Center for Applied Research.

Boud, D., \& Molloy, E. (2013). Rethinking models of feedback for learning: the challenge of design. Assessment \& Evaluation in higher education, 38(6), 698-712.

Campbell, J. P., DeBlois, P. B., \& Oblinger, D. G. (2007). Academic analytics: A new tool for a new era. EDUCAUSE review, 42(4), 40.

Cavalcanti, A. P., Diego, A., Mello, R. F., Mangaroska, K., Nascimento, A., Freitas, F., \& Gašević, D. (2020). How good is my feedback? a content analysis of written feedback. In Proceedings of the tenth international conference on learning analytics \& knowledge (pp. 428-437).

Cechinel, C., Ochoa, X., Lemos dos Santos, H., Carvalho Nunes, J. B., Rodés, V., \& Marques Queiroga, E. (2020). Mapping learning analytics initiatives in latin america. British Journal of Educational Technology, 51(4), 892-914.

Clow, D. (2012). The learning analytics cycle: closing the loop effectively. In Proceedings of the 2nd international conference on learning analytics and knowledge (pp. 134138).

\footnotetext{
${ }^{6}$ https://lalaproject.org
} 
Colvin, C., Dawson, S., Wade, A., \& Gašević, D. (2017). Addressing the challenges of institutional adoption. Handbook of learning analytics, 1, 281-289.

de Soria, I. M., Alonso, J., Orue-Echevarria, L., \& Vergara, M. (2009). Developing an enterprise collaboration maturity model: Research challenges and future directions. In 2009 ieee international technology management conference (ice) (p. 1-8).

De Laet, T., Millecamp, M., Ortiz-Rojas, M., Jimenez, A., Maya, R., \& Verbert, K. (2020). Adoption and impact of a learning analytics dashboard supporting the advisor-student dialogue in a higher education institute in latin america. British Journal of Educational Technology, 51(4), 1002-1018.

DMM. (2014). Modelo data management maturity - versão 1.0. CMMI Institute.

Dyckhoff, A. L., Zielke, D., Bültmann, M., Chatti, M. A., \& Schroeder, U. (2012). Design and implementation of a learning analytics toolkit for teachers. Educational Technology \& Society, 15, 58-76.

Falcao, T. P., Ferreira, R., Rodrigues, R. L., Diniz, J., \& Gasevic, D. (2019). Students' perceptions about learning analytics in a brazilian higher education institution. In 2019 ieee 19th international conference on advanced learning technologies (icalt) (Vol. 2161, pp. 204-206).

Ferguson, R., Clow, D., Macfadyen, L., Essa, A., Dawson, S., \& Alexander, S. (2014). Setting learning analytics in context: Overcoming the barriers to large-scale adoption. In Proceedings of the fourth international conference on learning analytics and knowledge (pp. 251-253).

Freitas, E., Fonseca, F., Garcia, V., Ferreira, R., \& Gašević, D. (2020). Towards a maturity model for learning analytics adoption an overview of its levels and areas. In 2020 ieee 20th international conference on advanced learning technologies (icalt) (pp. 122126).

Freitas, E. L. S. X., Souza, F. d. F. d., \& Garcia, V. C. (2019). Learning analytics em ação: Uma revisão sistemática de literatura. In Viii congresso brasileiro de informática na educação (cbie 2019) (p. 1581-1590).

Gašević, D. (2018). Include us all! directions for adoption of learning analytics in the global south. Learning analyfics for the global south, 1-22.

Gašević, D., Dawson, S., Rogers, T., \& Gasevic, D. (2016). Learning analytics should not promote one size fits all: The effects of instructional conditions in predicting academic success. The Internet and Higher Education, 28, 68-84.

Gašević, D., Dawson, S., \& Siemens, G. (2015). Let's not forget: Learning analytics are about learning. TechTrends, 59(1), 64-71.

Gašević, D., Tsai, Y.-S., Dawson, S., \& Pardo, A. (2019). How do we start? an approach to learning analytics adoption in higher education. The International Journal of Information and Learning Technology, 36(4), 342-353. 
Gewerc, A., Rodríguez-Groba, A., \& Martínez-Piñeiro, E. (2016). Academic social networks and learning analytics to explore self-regulated learning: a case study. IEEE Revista Iberoamericana de Tecnologias del Aprendizaje, 11(3), 159-166.

Greller, W., \& Drachsler, H. (2012). Translating learning into numbers: A generic framework for learning analytics. Educational Technology \& Society, 15(3), 42-57.

Guerra, J., Ortiz-Rojas, M., Zúñiga-Prieto, M. A., Scheihing, E., Jiménez, A., Broos, T., ... Verbert, K. (2020). Adaptation and evaluation of a learning analytics dashboard to improve academic support at three latin american universities. British Journal of Educational Technology, 51(4), 973-1001.

Gutiérrez, F., Seipp, K., Ochoa, X., Chiluiza, K., De Laet, T., \& Verbert, K. (2020). Lada: A learning analytics dashboard for academic advising. Computers in Human Behavior, $107,105826$.

Hattie, J., \& Timperley, H. (2007). The power of feedback. Review of educational research, 77(1), 81-112.

Hilliger, I., Ortiz-Rojas, M., Pesántez-Cabrera, P., Scheihing, E., Tsai, Y.-S., MuñozMerino, P. J., .. Pérez-Sanagustín, M. (2020). Towards learning analytics adoption: A mixed methods study of data-related practices and policies in latin american universities. British Journal of Educational Technology, 51(4), 915-937.

Lang, C., Siemens, G., Wise, A., \& Gašević, D. (2017). Handbook of learning analytics (1st ed.). Society for Learning Analytics Research.

Macfadyen, L. P., Dawson, S., Pardo, A., \& Gaševic, D. (2014). Embracing big data in complex educational systems: The learning analytics imperative and the policy challenge. Research \& Practice in Assessment, 9, 17-28.

Mello, R. F., André, M., Pinheiro, A., Costa, E., \& Romero, C. (2019). Text mining in education. Wiley Interdisciplinary Reviews: Data Mining and Knowledge Discovery, 9(6), e1332.

Miranda, P. B., Mello, R. F., Castro, M., Fiorentino, G., Souza, S., Santos, L., \& Silva, L. (2020). Uma abordagem multi-objetivo para seleção de caminhos de aprendizagem para grupo de usuários. Revista Brasileira de Informática na Educação, 27(03), 336.

Miranda, P. B., Mello, R. F., \& Nascimento, A. C. (2020). A multi-objective optimization approach for the group formation problem. Expert Systems with Applications, 162, 113828.

Norris, D., \& Baer, L. (2013). Building organizational capacity for analytics. louisville, co: Educause.

Pardo, A. (2018). A feedback model for data-rich learning experiences. Assessment \& Evaluation in Higher Education, 43(3), 428-438. 
Pardo, A., Jovanovic, J., Dawson, S., Gašević, D., \& Mirriahi, N. (2019). Using learning analytics to scale the provision of personalised feedback. British Journal of Educational Technology, 50(1), 128-138.

Passero, G., Ferreira, R., \& Dazzi, R. L. S. (2020). Off-topic essay detection: A comparative study on the portuguese language. Revista Brasileira de Informática na Educação, 27(03), 177.

Pontual Falcão, T., Ferreira Mello, R., \& Lins Rodrigues, R. (2020). Applications of learning analytics in latin america. British Journal of Educational Technology, 51(4), 871-874.

Pontual Falcão, T., Mello, R. F., Rodrigues, R. L., Diniz, J. R. B., Tsai, Y.-S., \& Gašević, D. (2020). Perceptions and expectations about learning analytics from a brazilian higher education institution. In Proceedings of the tenth international conference on learning analytics \& knowledge (pp. 240-249).

Raghuveer, V. R., \& Tripathy, B. K. (2014). Multi dimensional analysis of learning experiences over the e-learning environment for effective retrieval of los. In 2014 ieee sixth international conference on technology for education (p. 168-171).

Rolim, V., Ferreira, R., Lins, R. D., \& Găsević, D. (2019). A network-based analytic approach to uncovering the relationship between social and cognitive presences in communities of inquiry. The Internet and Higher Education, 42, 53-65.

Ruiz, J. S., Díaz, H. J. P., Ruipérez-Valiente, J. A., Muñoz Merino, P. J., \& Kloos, C. D. (2014). Towards the development of a learning analytics extension in open edx. In Proceedings of the second international conference on technological ecosystems for enhancing multiculturality (p. 299-306). New York, NY, USA: Association for Computing Machinery. Retrieved from https://doi.org/10.1145/2669711.2669914 doi: $10.1145 / 2669711.2669914$

Santos, J. L., Govaerts, S., Verbert, K., \& Duval, E. (2012). Goal-oriented visualizations of activity tracking: A case study with engineering students. In Proceedings of the 2nd international conference on learning analytics and knowledge (p. 143-152). New York, NY, USA: Association for Computing Machinery. Retrieved from https://doi.org/10.1145/2330601.2330639 doi: $10.1145 / 2330601.2330639$

Sclater, N., Peasgood, A., \& Mullan, J. (2016). Learning analytics in higher education. London: Jisc. Accessed February, 8(2017), 176.

Siemens, G., \& Baker, R. S. d. (2012). Learning analytics and educational data mining: towards communication and collaboration. In Proceedings of the 2nd international conference on learning analytics and knowledge (pp. 252-254).

Sun, J. C., Lin, C., \& Chou, C. (2016). Applying learning analytics to explore the influence of online learners' motivation on their online learning behavioral patterns. In 2016 5th iiai international congress on advanced applied informatics (iiai-aai) (p. 377$380)$. 
Tsai, Y.-S., \& Gasevic, D. (2017). Learning analytics in higher education-challenges and policies: a review of eight learning analytics policies. In Proceedings of the seventh international learning analytics \& knowledge conference (pp. 233-242).

Tsai, Y.-S., Moreno-Marcos, P. M., Jivet, I., Scheffel, M., Tammets, K., Kollom, K., \& Gašević, D. (2018). The sheila framework: Informing institutional strategies and policy processes of learning analytics. Journal of Learning Analytics, 5(3), 5-20.

Verbert, K., Duval, E., Klerkx, J., Govaerts, S., \& Santos, J. L. (2013). Learning analytics dashboard applications. American Behavioral Scientist, 57(10), 1500-1509.

Virvou, M., Alepis, E., \& Sidiropoulos, S. (2015). A learning analytics tool for supporting teacher decision. In 2015 6th international conference on information, intelligence, systems and applications (iisa) (p. 1-3).

Wendler, R. (2012). The maturity of maturity model research: A systematic mapping study. Information and Software Technology, 54(12), 1317 - 1339. Retrieved from http://www.sciencedirect.com/science/article/pii/s0950584912001334 (Special Section on Software Reliability and Security) doi: https://doi.org/10.1016/j.infsof.2012.07.007

Yassine, S., Kadry, S., \& Sicilia, M. (2016). A framework for learning analytics in moodle for assessing course outcomes. In 2016 ieee global engineering education conference (educon) (p. 261-266).

Young, J., \& Mendizabel, E. (2009). Helping researchers become policy entrepreneurs. Overseas Development Institute London, UK. 